\title{
SOFTWARE FOR MODEL PREPARATION OF TRANSMISSION LATTICE CONSTRUCTION
}

\author{
PAULECH Juraj ${ }^{1}$, GÁLIK Gabriel ${ }^{1}$, KUTIŠ Vladimír ${ }^{1}$, MURÍN Justín ${ }^{1}$

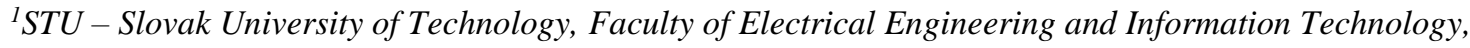 \\ Department of Applied Mechanics and Mechatronics, Ilkovičova 3, 81219 Bratislava, Slovakia \\ e-mail: juraj.paulech@stuba.sk,vladimir.kutis@stuba.sk,gabriel.galik@stuba.sk,justin.murin@stuba.sk
}

\begin{abstract}
This paper presents the preparation phase for model of transmission tower lattice construction using ANSYS APDL environment. Beam elements are used for the model which introduce complications in the preparation phase because of the need to define the beam shape. Considering that the lattice construction of the transmission tower consists of hundreds of trusses it is obvious that some auxiliary tool is necessary for preparation of such model in ANSYS APDL. This tool was programmed in SW Wolfram Mathematica.
\end{abstract}

KEYWORDS: beam element, lattice construction, transmission tower, APDL, Wolfram Mathematica

\section{Introduction}

The goal of the presented problem is to prepare a finite element model for transmission tower according to Fig. 1 for structural analyses like steady-state and modal analyses. The model should be relatively precise but the number of elements and nodes should be suitable for solutions calculated using midrange capability desktop PC. This requirement eliminates the utilization of link as well as 3D solid elements and leads to the beam element model. The benefit of the computational model formed using beam elements is that the geometry part consists of simple interconnected lines by their end points to form the 3D lattice of the tower construction and also the relatively simple discretization of the geometry model to finite element model. But disadvantages of the beam structure lie in relatively complicated definition of the shape, dimensions and offsets of cross-sections for individual trusses of the tower construction. Also their positioning and orientation in the given global coordinate system is not a simple task in the ANSYS APDL environment [1], considering the number of trusses that form the tower. All trusses of presented transmission tower have an "L" shaped cross-section. Individual "L" shaped cross-sections have identical thickness and length of arm i.e. bilateral symmetry (but dimensions of the "L" shaped cross-sections are not the same for all trusses).

\section{Program in SW Wolfram Mathematica}

For the given problem it is desirable to use some auxiliary tool that is able to prepare graphical preview of defined parts of the model in any time during the process of model creation and also that is able to calculate all necessary parameters for APDL code for the beam element model. We programmed such tool - code - in SW Wolfram Mathematica [2], as it is a powerful software in terms of many predefined functions for mathematical, database and text operations with simple and uniform syntax. 

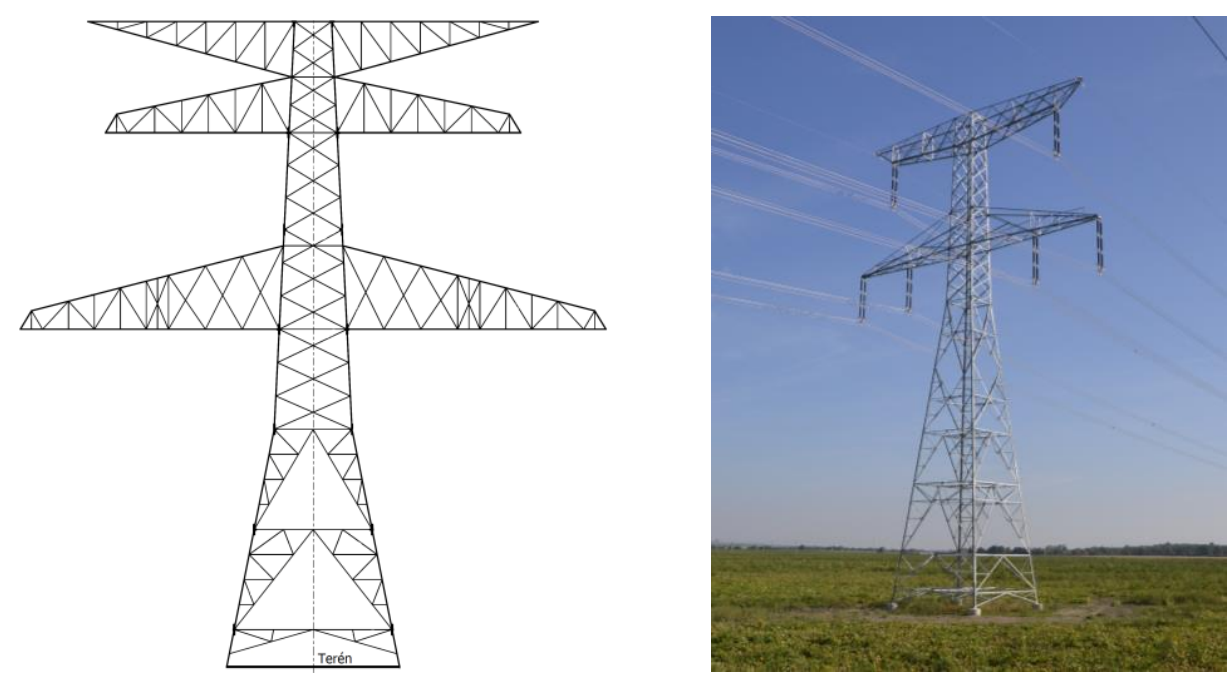

Fig. 1 Transmission tower lattice construction (left - anchor tower, right - support tower)

The code solves the problem of setting individual trusses of the tower structure by defining their origin and ending coordinates, defining dimensions of the "L" shaped cross-section that belong to a given truss and by defining a rotation and offset of the truss detached to main geometric line of the truss. All these parameters are input by the user via dialog input windows.

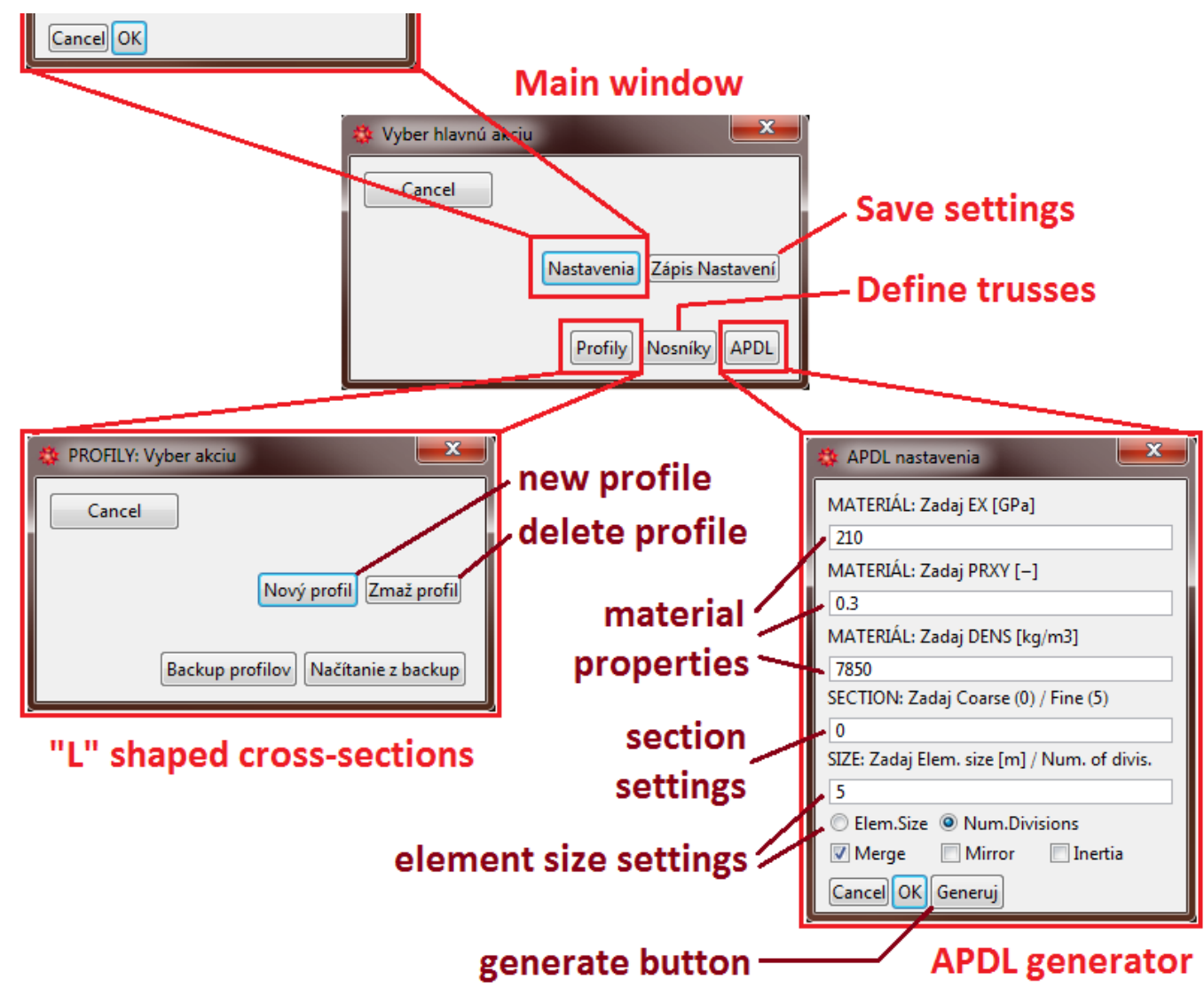

Fig. 2 Main actions in the program

In Fig. 2 we can see the main window of our code where we can choose one of the main actions: 
- to enter general settings for the program environment (triad arrangement, line width for graphical preview and resolution of the preview)

- to enter all dimensions of "L" shaped cross-sections used in the tower structure (it is possible to create a simple database of used cross-sections by defining the length of arms of the profiles and their thickness, also it is possible to delete unused profiles, backup and resume from backup of the profiles' database)

\section{New truss: Definition}

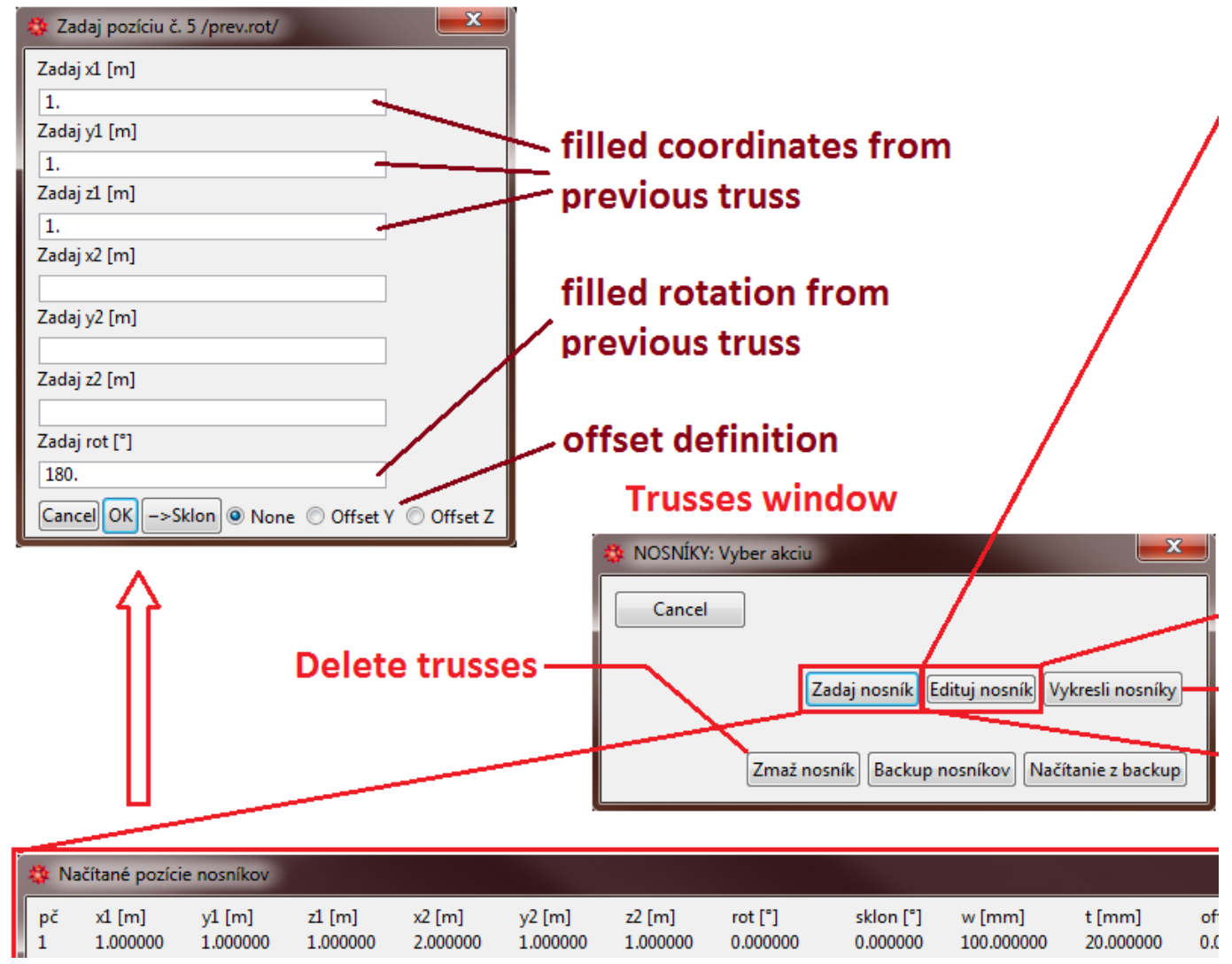

Fig. 3 Define trusses

Fig. 3 shows the dialog windows for trusses definition and processing. We can see there that we can:

- enter parameters for a new truss (list of previously defined trusses appears for user to have an overview about last actions defined in the system; then defining the parameters follows where user can fill automatically the starting coordinates and rotation for new truss that are copied from ending coordinates from previous truss - it is useful during creation of series of trusses connected one after another)

- edit parameters for last or chosen truss (user is able to edit incorrectly defined truss parameters)

- draw graphical preview of all or chosen trusses from database (for details see further figures and text)

- delete chosen truss or group of trusses

- backup trusses database or resume from backup

Fig. 4 shows graphical preview of four defined trusses (basic example). Final geometric and beam finite element model in ANSYS APDL environment is shown in Fig. 5. We can see that even the final geometric ANSYS model consists of only four simple connected lines 
(Fig. 5), the beam elements are positioned, rotated and offset properly according to graphical preview from our program (Fig. 4). Also we can see from these figures the presentation of different dimensions of "L" cross-sections, rotations and offsets defined for trusses. Moreover, we can see that the program calculates coordinates for orientation keypoints used in APDL environment (orientation keypoint is used for appropriate rotation of finite beam elements created along main geometric line of the truss).

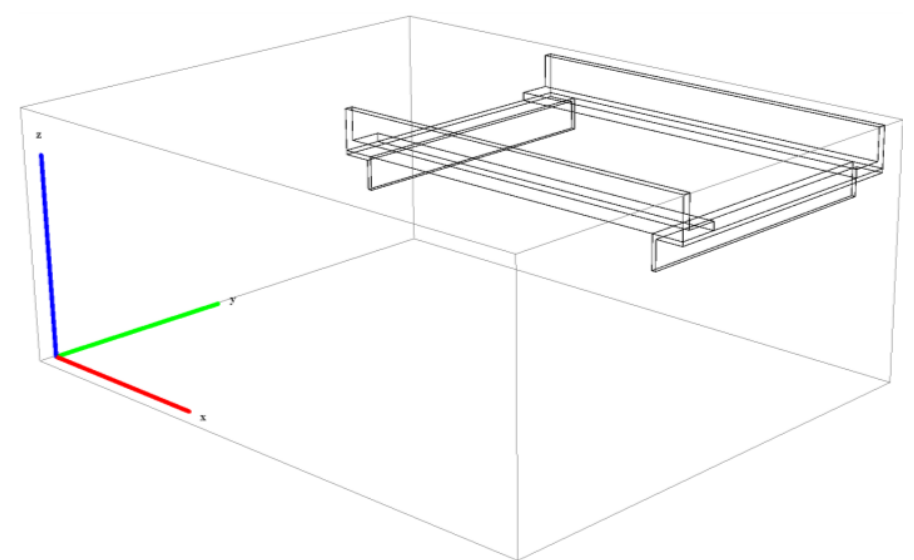

Fig. 4. Graphical preview of chosen trusses
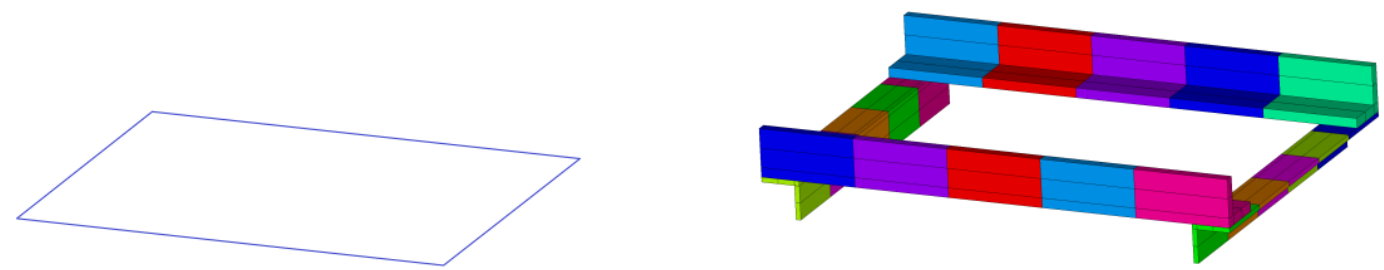

Fig. 5 ANSYS APDL geometric line model (left), Beam finite element model (right)

Graphical preview of trusses in our program is based on preparation of graphical wireframe shape of defined truss with parameters (length of the truss, dimensions of "L" cross-section, offsets) in the local coordinate system that is finally transformed into the global coordinates using transformation matrix. This process is shown in Fig. 6 where example of Mathematica syntax is presented.

- profil L

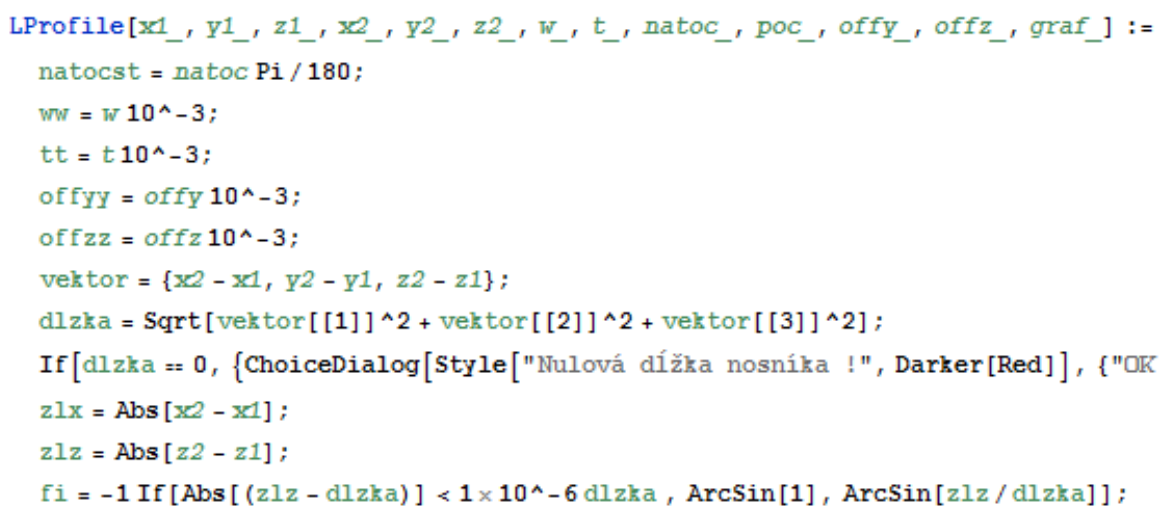

Fig. 6 Transformation from local to global coordinate system (example of Wolfram Mathematica syntax) 
Finally, programmed APDL generator prepares text file in working directory that can be directly read in ANSYS APDL environment.

\section{Beam model of the transmission tower lattice construction}

We used our program to prepare model of transmission tower (see Fig 1) using trusses finally represented by beam finite elements $[3,4,5]$. Due to symmetry of the whole structure it is possible to prepare only quarter geometric model and quarter beam model that is subsequently mirrored to form the full finite element model.

The quarter model that consists of 412 trusses is shown by graphical preview of our program in Fig. 7. There is also shown final APDL text file generated by our program, only the first and the last trusses are shown (i.e. commands for these trusses).
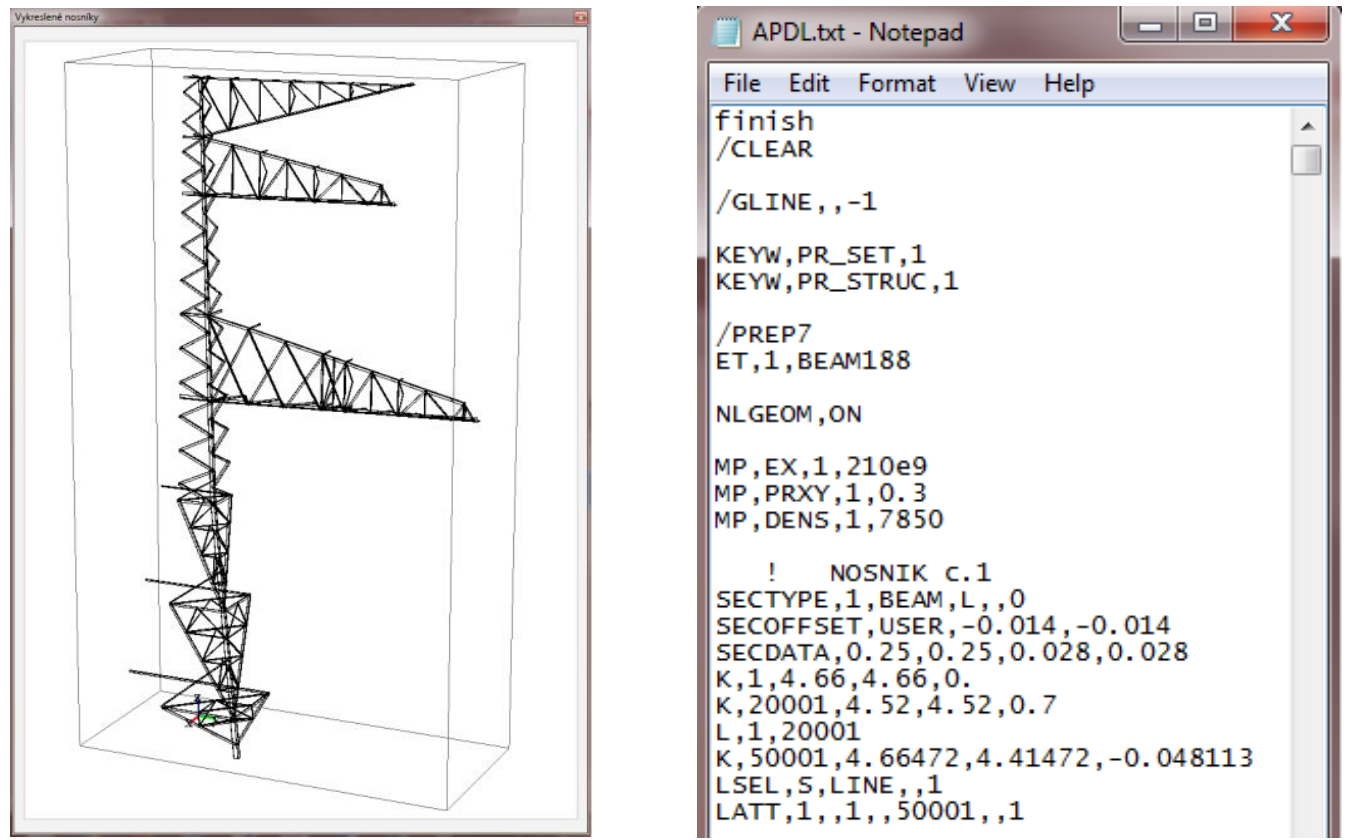

Fig. 7 Graphical preview of anchor transmission tower quarter model (left), generated APDL code with the first and the last truss defined (right)

Final model in ANSYS APDL environment with chosen details and beam mesh is shown in Fig. 8. There are over 12500 elements and over 24500 nodes used in the model. Results for the second eigen-shape of the transmission tower is shown in Fig. 9 (the tower is mechanically supported by endpoints of its legs; the second eigenfrequency is about $3 \mathrm{~Hz}$ ).
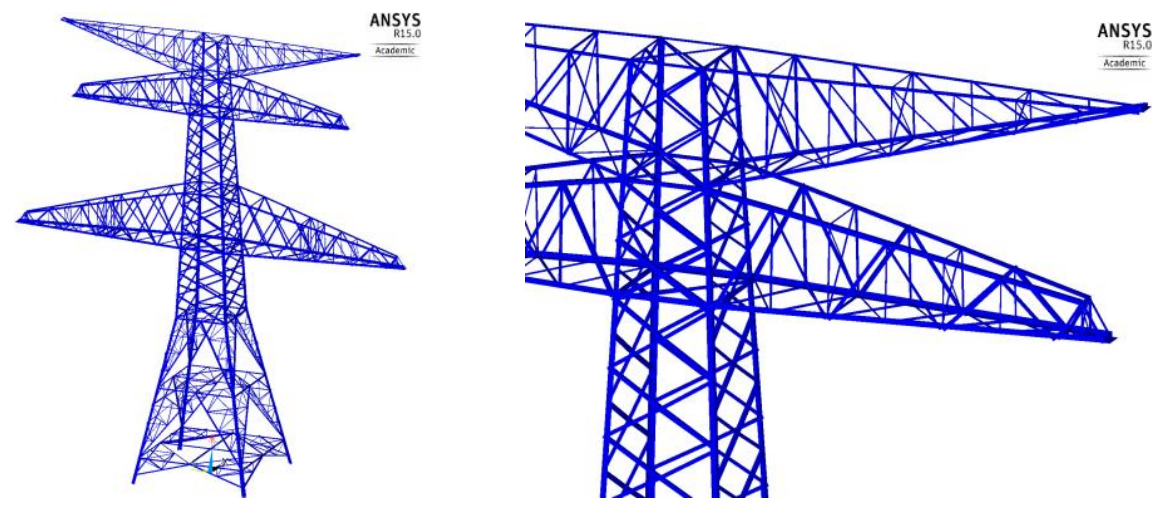

Fig. 8 ANSYS APDL beam finite element full model of transmission tower structure (left) and the detail of the model (right) 
Model of two span distances (AlFe power line) between anchor transmission towers (terminals) and support tower (middle, see also Fig. 1) are also shown in Fig. 9. This model was also used for modal and static simulations.

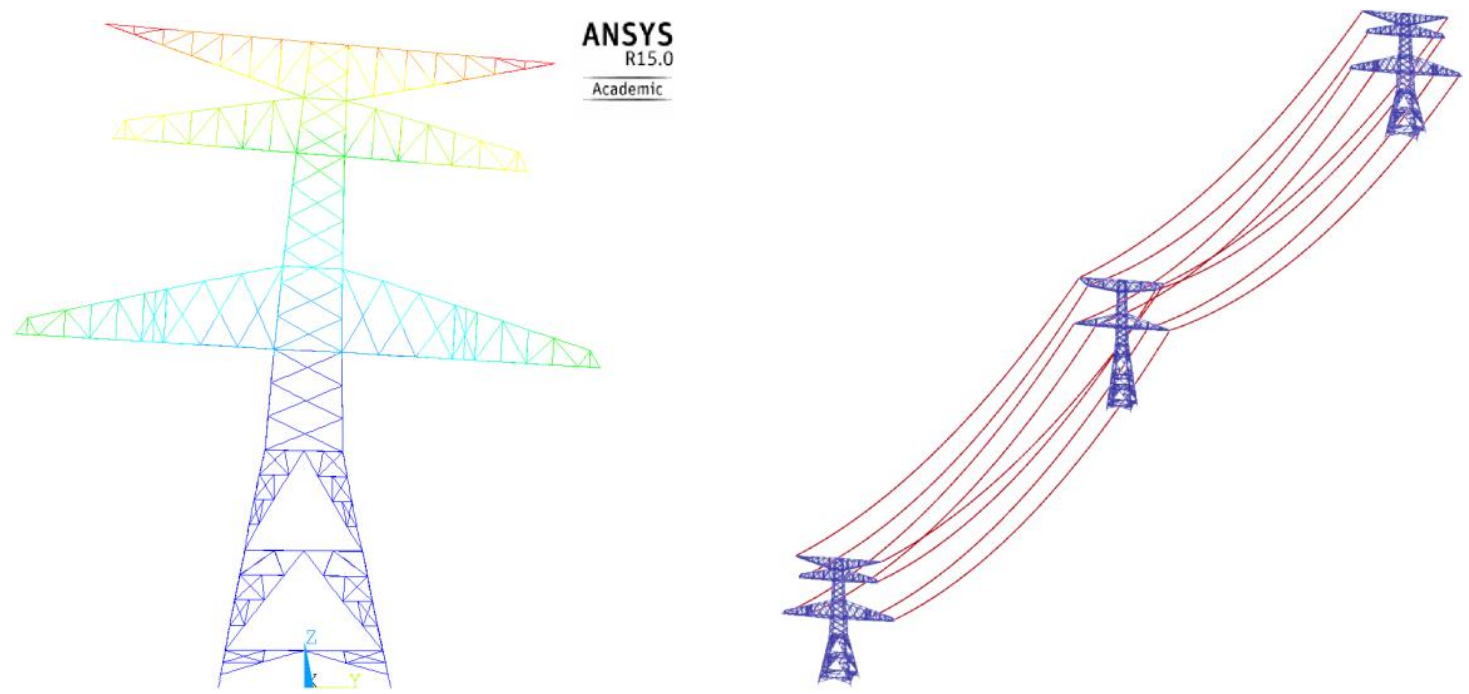

Fig. 9 The second eigen-shape of the tower structure - eigenfrequency $\approx 3 \mathrm{~Hz}$ (left) and beam model of span distances with AlFe power lines, two anchor towers and one support tower

(right)

\section{CONCLUSION}

The paper presented custom program for preparation phase for ANSYS APDL model that consist of number of trusses with different dimensions, rotation and offsets of "L" shaped crosssections. The presented program ensures good feedback to user that creates the model by graphic preview of chosen parts of the model, ensures management of the trusses database and finally automatically creates APDL text file with all necessary settings and definitions.

\section{ACKNOWLEDGEMENT}

This work was supported by the Slovak Grant Agency: VEGA No. 1/0102/18, VEGA No. 1/0081/18, APVV-14-0613 and APVV-0246-12. Authors are also grateful to the HPC Centre at the STU - SIVVP project, ITMS code 26230120002.

\section{REFERENCES}

[1] “ANSYS Swanson Analysis System”, Inc.: ANSYS Multiphysics, 201 Johnson Road, Houston, PA 15342/1300, USA, 2011.

[2] WOLFRAM, S. "Mathematica 5", Wolfram research, Inc., software, 2003.

[3] Benča, Š. "Výpočtové postupy MKP pri riešení lineárnych úloh mechaniky", Vydavatel'stvo STU Bratislava, 150 pp., 2006. ISBN 80-227-2404-1

[4] Hrabovský, J., Gogola, R., Murín, J., Sedlár, T. "Modeling of ice-shedding from ACSR power line", In: Strojnícky časopis - Journal of Mechanical engineering 67 (1), pp. 45 54, 2017. DOI: $10.1515 /$ scjme-2017-0005

[5] Šlesar, P., Jančo, R. "Press-fit evaluation and study of displacement in temperature changes", In: Strojnícky časopis - Journal of Mechanical engineering 68 (1), pp. 103 108, 2018. DOI: $10.2478 /$ scjme-2018-0011 